\title{
İçmimarlık ve Sürdürülebilirlik İlişkisi: Ekolojik, Ekonomik ve Sosyal/Kültürel Açıdan İnceleme *
}

\author{
Interior Architecture And Sustainability: A Review in terms of Ecological, \\ Economical And Social/Cultural
}

\author{
Arş. Gör. Meryem GEÇIMLİ ${ }^{1}$, Prof. Dr. Burak KAPTAN ${ }^{2}$
}

\begin{abstract}
Özet
İçmimarlık mesleği, doğası gereği doğal ve ekonomik kaynakları kullanarak insana fiziksel, psikolojik, kültürel ve sosyal anlamda etki etmektedir. İçmimar bu kullanım ve etkilerin her açıdan sonuçlarını öngörebilme yetisine sahip olmalı ve etik ilkelerden uzaklaşmamalıdır. Sürdürülebilirlik ise doğal, ekonomik ve sosyal/kültürel kaynakların korunması düşüncesi ve buna bağlı etkinlikler olarak tanımlanabilir. Bu çalışmanın amacı belirgin bir biçimde görülebilen ancak üzerinde oldukça az çalışılan sürdürülebilirlik ve içmimarlık ilişsisini detaylı olarak incelemektir. Bu ilişki hem kavramsal hem de uygulama boyutunda bulunmaktadır. Ekolojik boyutu öne çıkaran değerlendirme sistemleri, iç mekandaki yaşantıyla ilişkili tercihler, kullanım alışkanlıkları vb., ekonomik boyutu öne çıkaran yeşil tasarım ve sürdürülebilirlik etiketlerinin tercih edilirlikleri ve uzun vadede getirileri vb., sosyal/kültürel boyutu öne çıkaran toplumsal ilişkilerin geliştirilmesi ve ortak değerlerin korunması vb. konuların içmimarlık meslek disiplini içerisindeki yeri alanında yapılmış çalışmalar üzerinden değerlendirilecektir. Sonuçta elde edilen veriler ile içmimarın yükümlülük ve sorumlulukları ortak gelecek adına içmimarlık mesleği üzerine düşen görevler belirlenmiştir.
\end{abstract}

Anahtar Kelimeler: İçmimarlık, sürdürülebilirlik, sürdürülebilir tasarım, ekoloji, ekonomi, sosyal ve kültürel sürdürülebilirlik

Makale Türü: Araştırma makalesi

\begin{abstract}
The interior architecture profession influences human beings physically, psychologically, culturally and socially by using the natural and economic resources required by nature. The interior architect should have the ability to foresee the consequences of these uses and effects from all sides and should not move away from ethical principles. On the other hand sustainability can be defined as the thinking of conservation of natural, economic and social/cultural resources and related activities. The purpose of this study is to examine in detail the relationship between sustainability and interior architecture, which can be seen clearly but is rarely studied. Moreover this relationship is both conceptual and practical.The evaluation systems that emphasize the ecological dimension, preferences related to the indoor environment, usage habits, etc., the preferences of the green design and sustainability labels
\end{abstract}

\footnotetext{
* Bu çalışma, Prof. B. Burak KAPTAN'ın Anadolu Üni. Güzel Sanatlar Ens. İçmimarlık Anasanat Dalı Sanatta Yeterlik 20172018 Bahar Dönemi "IÇT 602B Tasarım Atölyesi” dersi kapsamında hazırlanmıştır.

${ }^{1}$ Anadolu Üniversitesi, İçmimarlık Bölümü, meryemgecimli@anadolu.edu.tr, Orcid ID: https://orcid.org/0000-0002-17761936

${ }^{2}$ Anadolu Üniversitesi, İçmimarlık Bölümü, Eskişehir, 26000, Türkiye, bkaptan@anadolu.edu.tr, https://orcid.org/0000-00024815-8179
} 
that emphasize the economic dimension, and the long term benefits etc., social relations that emphasize social/cultural dimension and protection of common values etc. will be evaluated on the basis of the studies carried out in the field of interior architecture profession discipline. As a result it is determined that obligations and responsibilities of interior architecture and the duties for the sake of our common future.

Keywords: Interior architecture, sustainability, sustainable design, ecology, economy, social and cultural sustainability

Paper Type: Research paper

\section{Giriş}

Günümüzün üzerinde en çok tartışılan konularının başında sürdürülebilirlik gelmektedir. Çeşitli ölçüm ve göstergeler üzerinden kaynakların azalması, küresel ısınma gibi sorunların giderek büyüdüğü gözlemlenebilmekte ve uluslararası düzeyde anlaşma, uygulama ve yaptırımlar gün geçtikçe artmaktadır. İçmimarlık mesleği mekan biçimlendirme sürecinde kaynak ve malzeme kullanımı gibi konular üzerinden ekolojik ve ekonomik etkilere sahiptir. Ayrıca kullanıcılarla yakın ilişkiler üzerinden kullanıcı davranışlarına sosyolojik ve kültürel açıdan da önemli etkileri bulunmaktadır. Bu çalışmada; içmimarlık mesleğinin sürdürülebilirlik ile olan ilişkisi sürdürülebilirliğin üç temel ayağı olan ekolojik, ekonomik ve sosyal/kültürel sürdürülebilirlik üzerinden eleştirel bir yaklaşımla incelenecektir.

\section{1. İçmimarlık ve Sürdürülebilirlik}

İçmimarlık, İç Mekan Tasarımı Yeterlilik Konseyi (Council for Interior Design Qualification: CIDA) tarafından; içmekan yapılanması için teknik ve yaratıcı çözümler üretmek şeklinde tanımlanmaktadır (CIDA, 2014). Bu tanımlamanın devamında işlevsellik ile birlikte iç mekanın kullanıcıların yaşam niteliğini ve kültürünü geliştirmeye yönelik olmasına işaret edilmektedir. Binanın konumu ve sosyal bağlamının da düşünülerek çevresel sürdürülebilirlik ilkelerine uygunluğunun altı çizilmektedir.

Sürdürülebilirlik ise, en çok bilinen tanımıyla, gelecek kuşakların gereksinimlerini karşılamalarına engel olmadan günümüzün gereksinimlerinin karşılanabilmesidir (WCED, 1987). Tasarım disiplinlerinin temel ilkesi olan imkanların en verimli şekilde kullanılması sürdürülebilirliğin tanımı ile uyumlu görünmektedir.

İçmimarlık ve sürdürülebilirlik ilişkisini inceleyen çok sayıda çalışma bulunmaktadır. Aktaş (2013) ekolojik ve yeşil tasarım yaklaşımlarını tartıştığı çalışmasında içmimarlığın yapı sektöründeki önemli rolüne dikkat çekmektedir. Aydınlatma, havalandırma, 1sıl konfor, izolasyon, bitirme ve yüzey işleme malzemelerinin iç mekandaki enerji ve emisyon etkilerini değerlendirmektedir. Jones (2008) iç mekanın donatım, ince yapı ve ekipmanlarında (furnishing, finishes and equipment) yeşil tasarım (insan sağlı̆ğını koruyan) ve sürdürülebilir tasarım (dünyanın sağlığını koruyan) üzerine yapılan belirlemelerin çevresel sorumluluğu yansıttığını vurgulamaktadır. $\mathrm{Bu}$ çalışmalarda da görüldügü üzere sürdürülebilirlik ve içmimarlık ilişkisi çoğunlukla ekolojik sürdürülebilirlik üzerinden değerlendirilmektedir. Ancak sürdürülebilirliğin üç temel ayağ 1 olduğu kabul edilen bir görüştür. Bu konuya tek boyutlu olarak bakılmasının birtakım eksiklikleri de beraberinde getirebileceği düşünülmektedir. 
Araştırmacılar tarafından büyük çoğunlukla kabul edilen görüşe göre; sürdürülebilirlik üç ayağa sahiptir. Bunlar; ekolojik, ekonomik ve sosyal-kültürel sürdürülebilirliktir. Bazı araştırmalar sosyal ve kültürel sürdürülebilirliği ayrı ayrı değerlendirerek dört farklı temel üzerine yoğunlaşmaktadırlar. Ancak bir kısım çalışmalarda ele alındığı üzere bu çalışma da da sosyal ve kültürel boyut birbirleriyle yakın ilişkiler barındırması ve toplumsal bir olguya işaret etmesi nedeniyle birlikte değerlendirilmektedir. Genel hatlarıyla bakıldığında içmimarlık ile bu üç ayağın yakın ilişkisi görülmektedir. İçmimarlık ve sürdürülebilirlik ilişkisini özetlemek gerektiğinde;

- $\quad$ İçmimarlık doğal kaynakların kullanımı, enerji ve su harcamaları üzerinden ekolojik sürdürülebilirlik ile doğrudan bir ilişkiye sahiptir.

- $\quad$ İçmimarlık ekonomik kaynakların kullanımı ve kişisel, toplumsal ve küresel çapta maddi harcamalar üzerinden ekonomik sürdürülebilirlik ile doğrudan bir ilişkiye sahiptir.

- $\quad$ İçmimarlık insan ve toplum üzerinde etkilere sahiptir. Değerler, kültürel kodlar ve sosyal ilişkilerin kurgulanmasındaki etkin rolü ile sosyal-kültürel sürdürülebilirlik ile doğrudan bir ilişkiye sahiptir.

Şekil 1. İçmimarlık ve sürdürülebilirliğin benzeşen birleşenleri

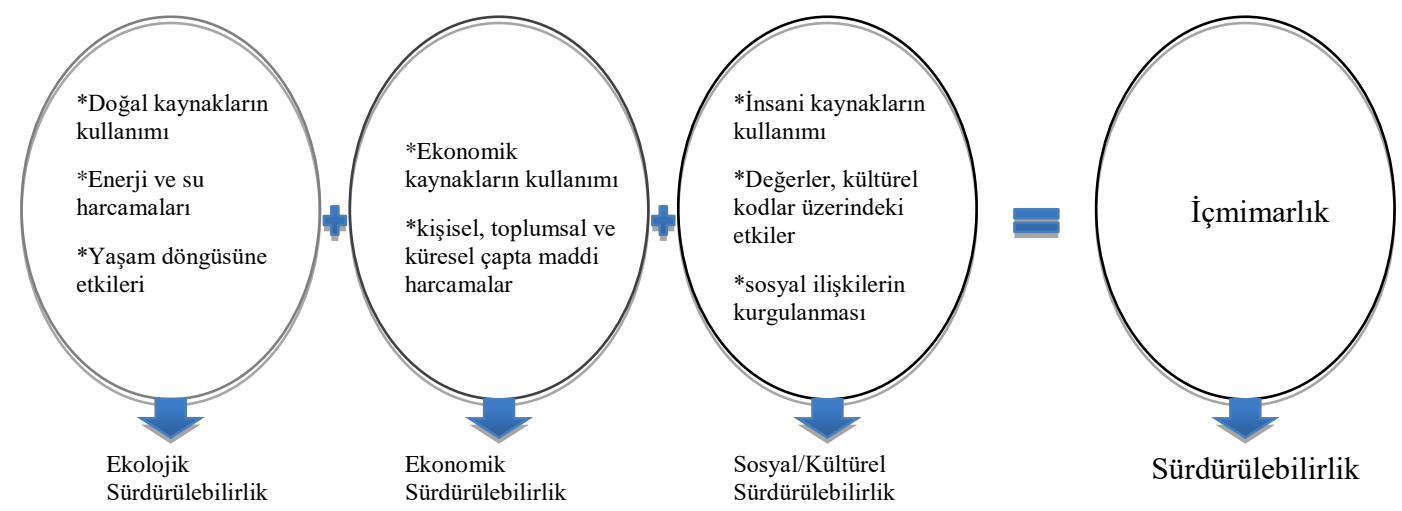

İçmimarlığın doğal, ekonomik ve sosyal/kültürel kaynaklara olan etkileri sürdürülebilirliği oluşturan üç temel ile ilişkilidir (Görsel 1). Ekolojik sürdürülebilirlik, ekonomik sürdürülebilirlik ve sosyal/kültürel sürdürülebilirlik ile olan ilişki çalışmanın devamında detaylandırılarak değerlendirilecektir.

\section{Araştırmanın Amacı ve Önemi}

İçmimarlık ve sürdürülebilirlik ilişkisini inceleyen önceki çalışmalar genellikle ekoloji temelini ele alarak konuya tek yönlü olarak yaklaşmışlardır. Bu çalışmada aynı anda ele alınacak bu üç boyut içmimarlık ve sürdürülebilirlik ilişkisine daha bütünsel ve karşılıklı ilişkilerinin görülüp değerlendirilebileceği bir nitelik katmaktadır. Çalışmanın amacı; içmimarlığın sürdürülebilirliğin üç temel ayağı ile aynı derecede ve önemde ilişkili olduğunu ortaya koymaktır. Bu ilişkinin belirlenmesi; 
- $\quad$ Mesleki farkındalığın artması sonucu nitelikli tasarımlar ortaya konmasını

• Gelecek öngörüsünün artması sonucu doğal, ekonomik ve sosyal/kültürel sürdürülebilirliğe katkıda bulunulmasını

- İçmimarların duyarlılığının artırılarak mesleğin geleceğinin şekillendirilmesini sağlaması açısından önem taşımaktadır.

\section{Araştırmanın Yöntemi}

Çalışmanın yöntemi iki aşamadan oluşmaktadır. Birinci aşama içmimarlık ve ekolojik, ekonomik ve sosyal/kültürel sürdürülebilirliği ele alan güncel ve temel kaynakların incelenmesinden oluşan kapsamlı bir literatür taramasıdır. İkinci aşamada ise ekolojik, ekonomik ve sosyal/kültürel sürdürülebiliğin içmimarlık ile olan ilişkisini belirlemeye yönelik detaylı analizden oluşmaktadır.

\section{Bulgular ve Tartışma}

\section{1. İçmimarlıkta Ekolojik Sürdürülebilirlik}

Uluslararası İçmimarlar Federasyonu (International Federation of Interior Architects/Designers: IFI) 2011 yılında yayınladığı ve yürürlükte olan iç mekan deklerasyonunda;

"Bizler alanı sorumlulukla kullanırız. Mesleğimizi, ekonomik ve doğal kaynakların sürdürülebilirlik esaslarına uygun şekilde kullanımını gözeterek uygularız. Bizler sağlık, güvenlik, refah ve kullanıcıların gereksinimleri için tasarlarız (IFI, 2011)"

ifadesi ile sürdürülebilirlik vurgusu yapılmaktadır. Uluslararası İç Mekan Tasarım Birliği (International Interior Design Association-IIDA) çeşitli yıllarda iç mekan tasarımında sürdürülebilirlik konuları üzerine yarışmalar, ulusal ve uluslararası etkinlikler düzenleyerek bu konuya olan desteğini göstermektedir. İçmimarlık ve ekolojik sürdürülebilirlik ilişkisi içmimarlığın uluslararası birliklerinde tanınarak önemsenmektedir.

Ekolojik sürdürülebilirliğin mekansal anlamda ölçümlenmesinde çeşitli standartlara dayandırılarak oluşturulmuş çevresel değerlendirme sistemleri günümüzün en yaygın uygulamalarındandır. Bu sistemlerden ilki olan Birleşik Krallık'ta geliştirilmiş "Building Researh Environmental Establishment Method" (BREEAM) ${ }^{3}$ ve Amerika Birleşik Devletleri'nde (ABD) geliştirilmiş "Leadership in Energy and Environmental Design $(\mathrm{LEED})^{4}$ dünya çapında yaygın olarak bilinen ve uygulanan değerlendirme sistemleridir. Binalara verilen bu etiket ve payeler kullanıcılar üzerinde de olumlu etkilere sahiptir. Nitekim Han, Hsu ve Sheu (2010) çalışmalarında otel misafirlerinin sürdürülebilirlik etiketine sahip otelleri tercih etmelerindeki nedenleri araştırmışlardır. Leaman ve Bordass (2007) ise konvansiyonel binalar ve yeşil binaların kullanıcıları arasında yaptıkları istatistiksel anket çalışmasında kullanıcıların yeşil binalara karşı daha toleranslı olduklarını ortaya koymuşlardır. Ayrıca kullanıcılar sürdürülebilir binaların imaj, gereksinimler ve sağlık açısından çok daha iyi olduklarını düşünmektedirler (Leaman ve Bordass, 2007).

\footnotetext{
${ }^{3}$ BREEAM: Birleşik Krallık’ta geliştirilmiş dünyanın ilk çevresel değerlendirme sistemidir.

${ }^{4}$ LEED: Amerika'da geliştirilmiştir ve günümüzde en yaygın uygulanan değerlendirme sistemidir. 
Başka bir çalışmada sürdürülebilirliği önemseyen otellerde kalan ziyaretçilerin bu otelleri tekrar ziyaret ederek çevrelerine tavsiye ettiklerini, bu otellerin özellikle kulaktan kulağa yaygınlaşan tanınırlıklarının olduğu sonucuna ulaşılmaktadır (Lee ve diğ, 2010).

Ayrıca ülkelerin kendi yerel koşulları ve hukuksal yapılarına uygun olarak oluşturdukları çok sayıda değerlendirme sistemi mevcuttur. Türkiye'de Çevre Dostu Yeşil Binalar Derneği'nin geliştirdiği ÇEDBİK-Konut ${ }^{5}$ dokuz başlık altında binaların çevresel değerlendirmesini yapmakta ve sertifika vermektedir. Bu değerlendirme sisteminde ilk başlık olan Bütünleşik Yeşil Proje Yönetiminin ön koşuldan sonraki ilk maddesi Entegre Tasarımdır ve iki puanlık karşılığı bulunmaktadır. Altı toplam puan içerisinde üçte birlik bir ağırlığa sahip olan bu alt başlıkta bina tasarım sürecinde uzman kişilerden oluşan bir ekip tanımlanmakta ve bu ekip içerisinde içmimarın da yer aldığı görülmektedir

Şekil 2. ÇEDBİK-Konut değerlendirme sistemi başlıkları

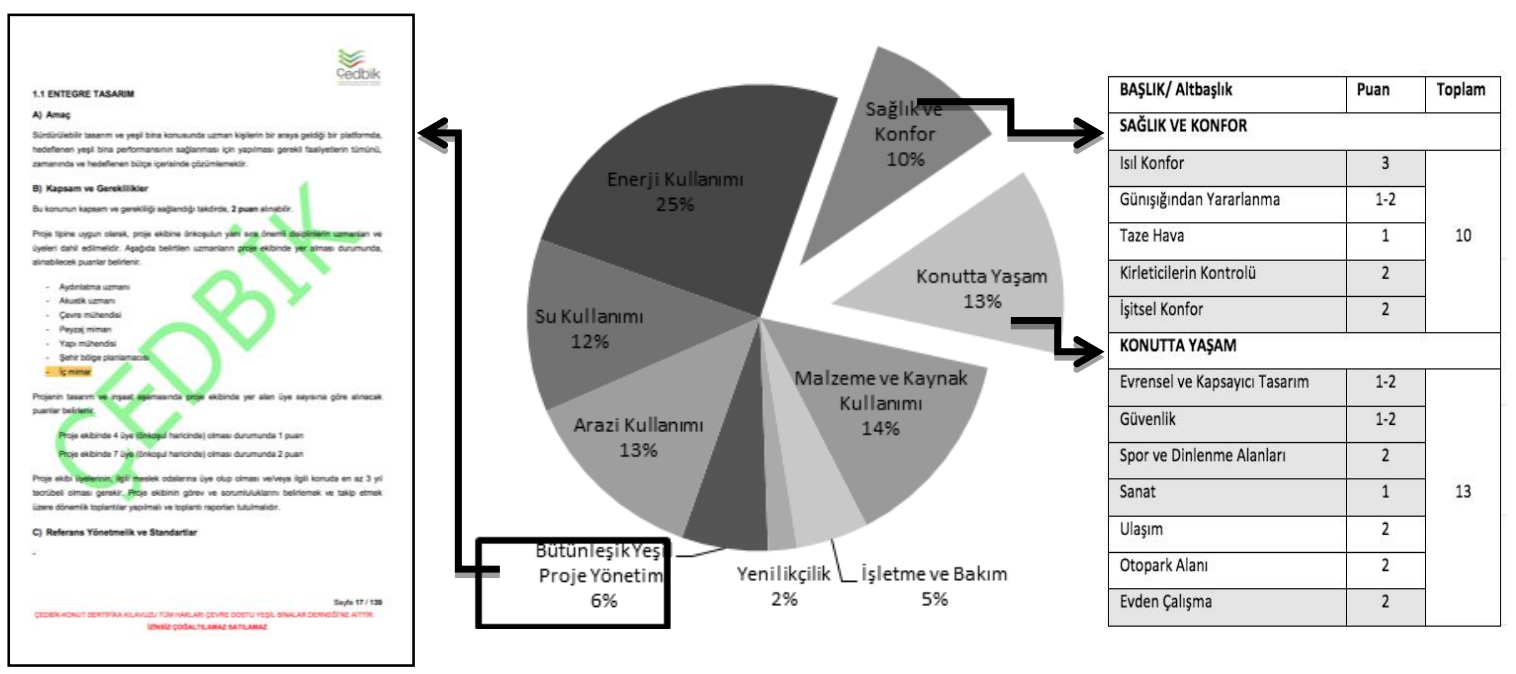

Ayrıca ÇEDBİK-Konut'un Sağlık ve Konfor ile Konutta Yaşam başlıkları içmimarlık mesleği ile oldukça yakından ilişkili konuları içermektedir. İki başlığın toplam 23 kredisi bulunmaktadır ve 100 puanlık sistemde \%23'lük bir ağılığa sahiptir. Görsel 2'de ÇEDBIKK-Konut'un içmimarlık ile doğrudan ilişkili iki başlı̆̆ Konfor" başlığı altındaki "Isıl Konfor", "Kirleticilerin Kontrolü" ve "İşitsel Konfor" altbaşlıkları içmimarlık ile doğrudan ilgili konular iken "Günışığından Yararlanma" ve "Taze Hava" altbaşlıkları ise dolaylı olarak içmimarlık ile ilgili konulardır. "Konutta Yaşam" başlığı altındaki "Ulaşım" ve "Otopark Alanı" dışındaki altbaşlıklarn tamamı ise doğrudan içmimarlık meslek disiplini içerisinde yer almaktadır.

${ }^{5}$ ÇEDBİK-Konut: Türkiye'de geliştirilmiş ve uygulanan ilk değerlendirme sistemidir. 


\section{2. İçmimarlıkta Ekonomik Sürdürülebilirlik}

İçmimarlık ekonomi ile yakın ilişkilere sahip bir meslek olarak düşünülmektedir. Kullanıcı ile birebir temas halinde bulunan bu meslek ekonomik dengelere etki etmektedir. Örneğin; bir çok katlı konutta yapısal açıdan 1sı izolasyonu iyi derecede yapılmış olsa bile her dairenin 1s1 giderleri birbirinden farkl1lık gösterebilir. Bunun nedenleri; yaşayan kişi sayısı, fizyolojik özellikler, özel bir takım durumlar, yaşam alanlarının tasarlanma biçimleri, kullanılan malzemelerin fizyolojik ve psikolojik etkileri olabilir. Her bir aile veya kişi ile birebir ilişki kurarak mekanları tasarlayan içmimar kişilerin 1sıl isteklerine bağlı olarak mekanları tasarlamaktadır. Bu açıdan ise enerji verimlilik duyarlılığına sahip bir içmimar tarafindan tasarlanmadan önce on birim enerji harcaması varken bu durumda beş birim veya daha azına düşürülebilir. Bu noktada anlatılmak istenen yalnızca enerji verimliliği sağlayan beyaz eşya, aydınlatma vb. tercihleri olmayıp malzemelerin fiziksel ve psikolojik etkileri, özel detay çözümleridir.

Tablo 1: İçmimarlık klasik anlamda bilinen mekan tasarım süreci ve sürdürülebilirliği sağlayan süreç

\begin{tabular}{|c|c|c|}
\hline \multicolumn{2}{|c|}{$\begin{array}{l}\text { KONVANSIYONEL TASARIM } \\
\text { SÜRECI }\end{array}$} & SÜRDÜRÜLEBİLIRLIĞİ SAĞLAYAN TASARIM SÜRECİ \\
\hline \multirow{11}{*}{$\begin{array}{c}\text { Veri } \\
\text { Toplama }\end{array}$} & \multirow[t]{5}{*}{ Tasarlanacak alan } & Bölgenin genel anlamda tüm ekolojik özellikleri \\
\hline & & Yakın çevrenin flora ve faunası \\
\hline & & Mevsimsel özellikler \\
\hline & & Hava kirliliği durumu \\
\hline & & Alanın yerden yüksekliğe bağlı manzara durumu \\
\hline & \multirow[t]{5}{*}{ Kullanicı } & Fiziksel özellikleri \\
\hline & & Karakter özellikleri \\
\hline & & Kültürel özellikleri \\
\hline & & Sosyal statüsü ve ilişkileri \\
\hline & & Sürdürülebilirlik bilinç düzeyi \\
\hline & Bütçe & Ayrılan bütçe \\
\hline \multirow{12}{*}{ Tasarlama } & \multirow{2}{*}{ Ana fikir geliştirme } & Sosyal/kültürel sürdürülebilirliğe katk1 sağlayacak fikirler geliștirilmesi \\
\hline & & Kullanıcının sürdürülebilirliğe yönelik bilincinin artmasına yönelik fikirlerin geliştirilmesi \\
\hline & \multirow[t]{7}{*}{ Malzeme araştırmaları } & Yerel malzemelerin araştırılması \\
\hline & & Üretim süreçlerinin ve yaşam döngüsünün araştırılması \\
\hline & & Sertifika ve standartlara uygunluğun incelenmesi \\
\hline & & İnsanın fiziksel ve psikolojik sağlığına etkilerinin belirlenmesi \\
\hline & & Ekolojik özelliklerinin araştırılması \\
\hline & & Ekonomik durumlarının (finansör, kullanıcı, yerel ve ulusal) belirlenmesi \\
\hline & & Sosyal/kültürel özelliklerinin sembolik değerlerinin araştırılması \\
\hline & \multirow[t]{3}{*}{ Detay çözümleri } & Sürdürülebilirliğe katk1 sağlayabilecek yenilikçi detayların geliştirilmesi \\
\hline & & Ekolojik sürdürülebilirliğe katk1 sağlayacak uygulanan detayların araştırılmas1 \\
\hline & & Tüm detayların ekonomik katkılarının ölçümlenmesi \\
\hline \multirow{3}{*}{ Sunum } & \multirow{3}{*}{$\begin{array}{l}\text { Eleştrilere göre } \\
\text { revizelerin yapılması }\end{array}$} & Gerekirse projenin ekonomik dengeyi sağlamasına yönelik revizeler yapılması \\
\hline & & Projenin sosyal statü ve ilişkileri düzenlemesine yönelik revizeler yapılması \\
\hline & & Projenin kültürel kodlar ve sembollere yönelik revizesinin yapılması \\
\hline \multirow{4}{*}{ Uygulama } & \multirow{3}{*}{$\begin{array}{l}\text { Fabrika/atölyede } \\
\text { üretim sürecinin } \\
\text { yönetimi }\end{array}$} & Üretim yapılacak fabrika/atölyenin ürünlerinde VOC testi yapılmış ve belgelendirilmiş olması \\
\hline & & Ahşap üretiminde endüstriyel ormanlardan hammadde elde edildiğinin belgelendirilmiş olması \\
\hline & & Üretim yerinin iș sağlığı ve güvenliği sertifikasının bulunması \\
\hline & $\begin{array}{l}\text { Yerinde uygulama } \\
\text { sürecinin yönetimi }\end{array}$ & $\begin{array}{l}\text { Oluşabilecek bütün atık kalemlerinin tür, niteliki miktar ve akıbetinin dökümantasyonunun önceden } \\
\text { yapılması }\end{array}$ \\
\hline
\end{tabular}




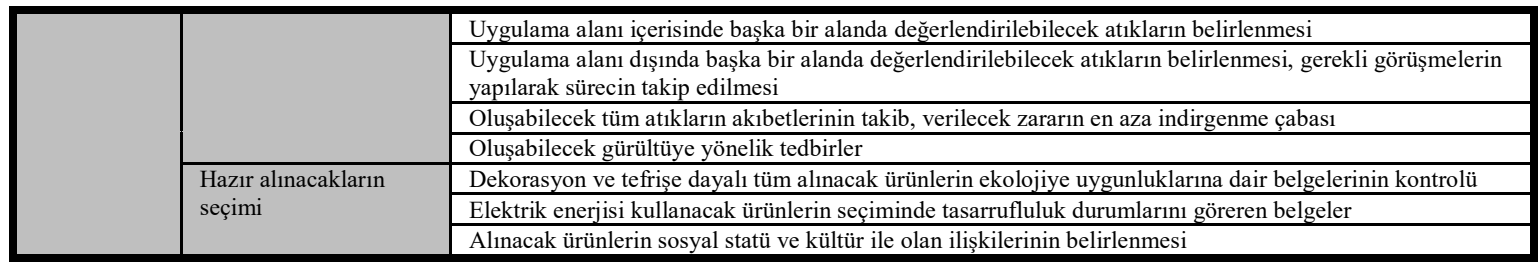

Tablo 1'de içmimarlıkta konvansiyonel anlamda mekan tasarım süreci ile sürdürülebilirliği sağlayan detaylandırılmış süreç görülmektedir. Bütçe ile ilgili kalemlerin yoğunluğu ve bütçenin yönetimi ile ekonomik sürdürülebilirlik ile olan ilişkinin önemi bu tablodan da rahatlıkla okunabilmektedir. Günümüzde yaygın olarak kullanılan konvansiyonel tasarım sürecine sürdürülebilirlik ile ilgili adımların detaylanarak eklenmesi sonucu böyle bir tablo elde edilmiştir. Bu tablodaki adımlar daha detaylandırılıp üzerine eklemeler ve geliştirmeler yapılarak sürdürülebilirliğe daha çok katkı sağlamak mümkündür ve gereklidir. Veri toplama sürecinde bütçe ile ilgili veriler oldukça önemlidir ve ekonomik sürdürülebilirliğe etki etmektedir. Yine tasarlama sürecinin hemen her adımında bütçe, maliyet ve kaynak kullanımı ile ilgili adımlar bulunmaktadır. Sunumda ise ekonomik katkı üzerine aktarımlar kullanıcı/müşteriyi ikna ve kararlarını yönlendirmede oldukça belirleyici olduğu kabul edilmektedir. Uygulama süreci yerel, ulusal ve uluslararası ekonomiye katkıları bulunan oldukça önemli bir adımdır.

Diğer yandan sürdürülebilirlik ile ilgili olan her türlü etiket ve özellikler giderek artan bir ilgiyle inşaat sektöründe yer edinmektedir. Yapılan araştırmalar enerji etkinliği, sürdürülebilirlik, yeşil tasarım gibi konuların bir yerin sahipleri ve orada geçici bulunanlar üzerinde olumlu etkiler bıraktığını ve daha yüksek maliyete sahip olsa bile ileri süreçte kazancın yüksekliğinden dolayı daha çok tercih edildiklerini ortaya koymaktadır. Feige, McAllister ve Wallbaum (2013) İsviçre'de 2500 konut yapısı üzerinde yaptıkları çalışmada konut yapılarında çevresel performans ve kiralama fiyatları arasında pozitif bir ilişkinin bulunduğunu belirlemişlerdir. Özellikle su tasarrufu sağlayan, sağlık ve konfor düzeyleri yüksek olan, güvenlik ve emniyeti sağlayan konutların fiyatlarının da diğer konutlara oranla daha yüksek olduğunu ortaya koymuşlardır. Fuerst, McAllister, Nanda ve Wyatt (2016) yaptıkları benzer bir çalışmada ise enerji performans sertifikalarına sahip konutlar ile fiyatları arasında olumlu bir ilişkinin varlı̆ğ sonucuna ulaşmışlardır. Beklenenin aksine düşük enerji performansına ve dolayısıyla düşük fiyata sahip konutların diğerlerine göre daha az ticaretinin yapılabildiğini ortaya koymuşlardır. Benzer bir çalışmayı Cajias ve Piazolo (2013) Alman konut sektörü üzerinde yürütmüşlerdir. Yasal ve bağlayıcı düzenlemelerin de etkisiyle kiralayıcıların enerji verimliliği talep ettiklerini ve ev sahiplerinin de bu konuda yatırımları giderek arttırdıkları sonucuna ulaşmışlardır.

\section{3. İçmimarlıkta Sosyal/Kültürel Sürdürülebilirlik}

Sürdürülebilirlik ile ilgili mekansal tasarım alanında çalışmalar çoğunlukla "yeşil" kavramı ile ekolojik sürdürülebilirlik üzerinde yoğunlaşmaktadır (Bergman, 2011; Tabb ve Deviren, 2013). Ekolojik ve/veya çevresel tasarım kavramı üzerinden ise karbon ayak izi, malzemeler ve malzemelerin yaşam döngüsüne vurgu yapılmaktadır (Yeang, 1995; Stitt, 1999). Tasarımda ekonomik sürdürülebilirlik ile ilgili çalışmalar ise tüketimin sürdürülebilirliği için tasarım ve bu tasarımların doğa ile olan ilişkileri üzerinden değerlendirilmektedir (Jackson, 2006; Thorpe, 2010). Ekolojik ve ekonomik sürdürülebilirliğin tasarımla olan ilişkileri literatürde geniş yer tutmaktadır. Bu çalışmaların 
giriş cümlelerinde "sürdürülebilirliğin ekolojik, ekonomik sosyal ve/veya kültürel ayaklarının bulunduğu"na vurgu yapılmakta ancak konunun kapsamının genişliği gereği tek bir boyutuna (çoğunlukla da ekolojik boyutuna) çalışılmaktadır.

Thorsby (2008) ekonomik kavramlar üzerinden ele aldığı sürdürülebilirliği doğal sermaye (natural capital) ve kültürel sermaye (cultural capital) şeklinde ayırmaktadır. Ona göre sürdürülebilir gelişmenin temelini doğal sermaye oluşturmakta ancak gelecek ve şimdiki kuşaklar arasında sağlanması gereken eşitliğin temelini de kültürel sermaye oluşturmaktadır. Chiu (2004) sosyal sürdürülebilirliğin üç yorumuna dikkat çekmektedir. Bunlar;

- Gelişme odaklı yorumlama: sürdürülebilirlik ile ilgili eylemin sosyal yapıda ve ilişkilerde, geleneklerde ve değerlerde yer tutması gerekmektedir,

- Çevre odaklı yorumlama: bu yorumlama ilk yorumlamanın daha derinleşmesi olarak görülmektedir. Doğal kaynaklar kuşaklar içinde ve kuşaklar arası nasıl bir dağılım göstermektedir,

- İnsan odaklı yorumlama: Bu yorumlamada insanın yaşam kalitesinde sosyal kaynaşma, bütünlük ve istikrar amaçlanmakta ve bu yolla sürdürülebilirliğin sağlanacağı düşünülmektedir.

Kültür ise ünlü antropolog Amos Rapoport'un söylemi ile genel anlamda üç tanıma sahiptir. Bunlar;

- $\quad$ Bir grubun yaşam tarzi,

- Kodlarla iletilen semboller, anlamlar ve bilişsel şema sistemler, stratejiler.

- Ekoloji ve kaynaklarla ilişkili olarak hayatta kalabilmek için geliştirilen

dir (Rapoport, 1980). Bir kültürel kaynak olarak mekan; geçmişin bir yansıması aynı zamanda da geleceğin bir şekillendiricisidir (Wu, Fan ve Chen, 2016). Sosyal ve kültürel yapı arasında birbirini tamamlayan ilişkiler olduğu kapsam ve detaylarda görülebilmektedir.

Sürdürülebilir tasarım ile ilgili güncel çalışmalarda sosyal/kültürel sürdürülebilirlik sıklıkla kullanılan bir kelime haline gelmeye başlamıştır. Ancak soyut bir takım değerlerden meydana gelmesi nedeniyle uygulamada oldukça az yer almaktadır. Yeşil binalarla ilgili standartlarda, sertifikasyon sistemlerinde ise sınırlı bir takım uygulamaları bulunmaktadır.

İçmimarlık, bireyin özel yaşam ve çalışma alanından toplumun kullandığı kamusal içmekanları şekillendirmeye kadar geniş bir alanda hizmet vererek bu mekanlar üzerinden sosyal ve kültürel yapıyı etkilemektedir. Rapoport'un vurguladığı "ev formu-kültür" ilişkisi (Rapoport, 1969) içmimarlık ile daha da artmaktadır. Kültürel kodlar ve semboller kentsel ve yapısal öğelerden ziyade iç mekanlarda, detaylarda ve özel alanlarda kendisini göstermektedir. Örneğin Geleneksel Türk Konut'unu özel ve kültürel kılan onun yapısal özelliğinden çok iç mekan organizasyonudur (Küçükerman,1988). Olesen (2010) etnik nesnelerin iç mekanda atmosfer oluşturma ve "evi ev yapma" hissini araştırdığ çalışmasında üst ve orta gelir grubu beyaz amerikan kadınları ile görüşmüştür. Çalışma sürecinde aldığı yanıtların ortak yönü bu etnik nesnelerin modern ve soğuk evlere sıcak, samimi ve kültürel 
bir atmosfer katmasıdır. İçmimar mekanı tasarlama sürecinde kültürel kodları kullanarak kültürel sürdürülebilirliğe katkı sağlamaktadır.

Sosyal ilişkiler ise yine daha özel alanların ve iç mekanların kurgusunda şekillenebilmektedir. Bir kentsel mekanın dümdüz bir arazi olması düşünülemez. Toplumun kullandığı kentsel mekanları anlamlı hale getiren ve bireyler arası ilişkileri sağlayan "kentsel iç”lerin birleşimi ile anlamlı bir hale gelmektedir(Grobler, 2006). İçmimar tasarladığı mekanlar üzerinden sosyal ilişkilerin geliştirilmesi ve sürdürülebilirliğinin sağlanmasına olanak sağlayabilmektedir.

\section{Sonuç Ve Öneriler}

Sonuç olarak içmimarlık ve sürdürülebilirlik ilişkisinin incelendiği bu çalışmada sürdürülebilirliğin üç temel ayağı olarak kabul edilen ekolojik, ekonomik ve sosyal/kültürel sürdürülebilirlik ayrım gözetmeksizin ele alınmıştır. İçmimarlık mesleğinin her üçü ile de yakından ve ayrılamaz bağları bulunmaktadır. Bu bağlar dikkatli bir şekilde incelenip ele alındığında sürdürülebilirlik kapsamında içmimarlığın önemi daha da artmaktadır. Özetle bu ilişki incelendiğinde;

- Doğal kaynakların etkin kullanımı yeni yapılarda olduğu kadar iç mekanı yenilenen projelerde de oldukça önemlidir. İ̧̧mimar bu süreçte verdiği kararlar ve kullanıcı üzerindeki etkisi ile ekolojik sürdürülebilirliğe katkı sağlayabilmektedir. Ayrıca binaların çevresel performansını ölçümleyen değerlendirme sistemlerinde içmimarlık ile ilgili pek çok başlık bulunmaktadır.

- Ekonomik kaynakların etkin kullanımı ekolojik sürdürülebilirlik kadar öneme sahip ikinci başlıktır. Kişisel, yerel, ulusal ve uluslararası ekonomiyi zincirleme bir şekilde etkileyebilecek kararları verebilme yetisi de yine içmimarlığın meslek alanı içerisindedir. Ayrıca da sürdürülebilirlik ile ilgili etkikete sahip mekanların olumlu anlamda çekiciliğe sahip ve tercih edilebilirliği de artmaktadır.

- İnsana ait kaynaklar olarak kabul edebileceğimiz sosyal olma durumuna ve kültüre içmimarlığın etkileri ise oldukça fazladır. Sosyal ilişkilerin güçlenmesi ve kültürün sürdürülebilirliğinin sağlanması içmimarın mekansal tasarımda kültürel ve sosyal kodları dikkatli bir şekilde kullanmasına bağlıdır.

Bu ilişkinin tanımlanması içmimarın sürdürülebilirlik ile ilgili olarak yükümlülük ve sorumluluklarının da belirlenmesine olanak sağlayabilmektedir. Bu sorumluluk ve yükümlülükler kısaca özetlenecek olursa;

- İçmimar, ekolojik sürdürülebilirliğe katk1 sağlayacak konuları araştırıp, güncel çalışmalardan haberdar olmalıdır. Geri dönüşüm-yeniden kullanım, malzeme ve mekanların yaşam döngüsü, enerji ve su korunumu vb. konularda güncel çalışmaları ve yapılmış tasarımları düzenli olarak takip ederek proje ve uygulamalarına eklemelidir. Ayrıca mevcut teknoloji ve uygulamaları geliştirerek yaratıcı ve yenilikçi çözümler geliştirme konusunda istekli olmalıdır.

- İçmimar, ekonomik sürdürülebilirliğe katk1 sağlayacak girişimler ve düzenlemelerde bulunmalıdır. Yerel, ulusal ve uluslararası ekonomik dengeleri 
takip ederek kullanıc1/müşterinin bütçesinin etkin bir şekilde harcanmasını sağlamalıdır. Önceki maddede bahsedilen ekolojik, geri dönüşüm-yeniden kullanıma tabi, enerji ve su etkin tasarımlar aynı zamanda ekonomik sürdürülebilirlik ile de yakından ilgilidir.

- İçmimar, sosyal/kültürel sürdürülebilirliğe katkı sağlaması gerekliliğini kabul etmeli ve kullanıcının içerisinde bulunduğu sosyal ve kültürel yapıyı doğru ve detaylı bir şekilde okumalıdır. İçmimar, kullanıcının sosyal ilişkilerini geliştirmesinde etkin rol oynamaktadır ve bu durumu olumlu anlamda kullanarak sosyal sürdürülebilirliğe katkı sağlamalıdır. Ayrıca kullanıcının içerisinde bulunduğu kültürel zenginliği araştırıp ortaya çıkarmalı ve bunun sürdürülmesini sağlamalıdır.

İçmimarın yükümlülük ve sorumluluklarının farkında olarak tasarım yapması ise ortak geleceğimiz açısından hayati öneme sahiptir.

\section{Kaynakça}

Aktaş, G. G. (2013). "Design Parameters and Initiatives for Ecological and Green Design in Interior Architecture", WSEAS Transactions on Environment and Development, 2(9):5767.

Bergman, D. (2011). Sustainable Design: A critical guide for architects and interior, lighting and environmental designers. New York: Princeton Architectural Press

Cajias, M. ve Piazolo, D. (2013). "Green performs better: energy efficiency and financial return on buildings", Journal of Corporate Real Estate, 15(1):53-72

Chiu, R. L. (2004). "Socio cultural sustainability of housing: a conceptual exploration", Housing, Theory and Society, 21(2):65-76 doi: 10.1080/14036090410014999

Council for Interior Design Qualification (2004). "Definition of Interior Design", https://www.cidq.org/definition-of-interior-design, (Erişim tarihi: 25.05.2018)

Feige, A., McAllister, P. ve Wallbaum, H. (2013). "Rental price and sustainability raitings: which sustainability criteria are really paying back?", Construction Management and Economics, 31(4):322-334 doi: 10.1080/01446193.2013.769686

Fuerst, F., McAllister, P., Nanda, A. ve Wyatt, P. (2016). "Energy performance ratings and house prices in Wales: AN emprical study", Energy Policy, 92: 20-33

Grobler, A. (2006). The Relation Between Spatial Definition and Place-Making: architectural and urban interiors. University of Pretoria, Master of Interior Architecture, Pretoria.

Han, H., Hsu, L-T., ve Sheu, C. (2010). "Application of the theory of planned behaviour to green hotel choice: Testing the effect of environmental friendly activities", Tourism Management, 31(3):325-334. doi:10.1016/j.tourman.2009.03.013.

Hawkes, J. (2001). The Fourth Pillar of Sustainability: Culture's essential role in public planning. Cultural Development Network (Vic)

International Federation of Interior Architects/Designers (2011). "IFI İç Mekan Deklerasyonu", https://ifiworld.org/wp-content/uploads/2017/01/IFI-InteriorsDeclaration_Turkish.pdf, (Erişim tarihi: 29.03.2018).

International - Interior Design Association (1994). "Search Results", http://www.iida.org/content.cfm/search?paramKeywords=sustainability \&x=0\&y=0, (Erişim tarihi: 29.03.2018).

Jackson, T. (2006). "Readings in Sustainable Consumption", İçinde: The Earthscan Reader in Sustainable Consumption. (Ed. T. Jackson). London: Earthscan. 
Jones, L. (2008). "Environmentally Responsible Interior Design”, İçinde: Environmentally Responsible Design: Green and Sustainable Design for Interior Designers. (Ed. L. Jones). New Jersey: John Wiley \& Sons Inc,

Kang, M. (2009). "The Characteristics of Interior Designers Who Practice Environmentally Sustainable Interior Design", Environment and Behaviour, 41(2):170-184

Küçükerman, Ö. (1988). Kendi Mekanının Arayışı içinde Türk Evi, İstanbul: Türkiye Turing ve Otomobil Kurumu

Leaman, A. ve Bordass, B. (2007). “Are Users More Tolerant of 'green' Buildings?”, Building Research and Informantion, 35(6):662-673 doi: 10.1080/09613210701529518.

Lee, J., Hsu, L., Han, H. ve Kim, Y. (2010). "Understanding How Consumers View Green Hotels: How a Hotel's Green Image Can Influence Behavioural Intentions". Journal of Sustainable Tourism, 18(7):901-914 doi: 10.1080/09669581003777747

Marshall-Baker, A. (2008). "Nature as a Model for Design", İçinde: Environmentally Responsible Design: Green and Sustainable Design for Interior Designers. (Ed. L. Jones). New Jersey: John Wiley \& Sons Inc.

Moxon, S. (2012). Sustainability in Interior Design, London: Laurence King Publinshing Ltd.

Olesen, Bodil. B. (2010). "Ethnic Objects in Domestic Interiors: space, atmosphere and the making of home". Home Cultures. 7(1):25-41 doi: 10.2752/175174210X12572427063760

Rapoport, A. (1980). "Cross-Cultural Aspects of Environmental Design”, İçinde: Human, Behaviour and Environment: Advances in Theory and Research (Ed. I. Altman, A. Rapoport, ve J. F. Wohwill). New York: Pleanum

Rapoport, A. (1969). House Form and Culture, Upper Saddle River, N.J.: Prentice Hall

Stitt, F. A. (1999). Ecological Design Handbook: Sustainable design strategies for architeture, landscape architecture, interior design and planning, London: McGraw Hill.

Tabb, P. J. ve Deviren, A. S. (2013). The Greening of Architecture: A critical history and survey of contemporary sustainable architecture and urban design, Surrey: Ashgate

Thorpe, A. (2010).”Design's Role in Sustainable Consumption”. Design Issues. 2(26):3-16

Thorsby, D. (2008). "Linking Ecological and Cultural Sustainability" International Journal of Diverse Organizations Communities Nations. 8(1):15-20

WCED (1987). "Our Common Future", The World Commision on Environment and Development. http://www.un-documents.net/our-common-future.pdf (Erişim tarihi: 25.05.2018)

Wu, S. R., Fan, P. ve Chen, J. (2016). "Incorporating Culture Into Sustainable Development: A cultural sustainability index framework for green buildings", Sustainable Development, 24:64-76

Yeang, K. (1995). Designing with Nature: The ecological basis for architectural design, New York: McGraw Hill.

Yılmaz, T. (2015). Sürdürülebilirlik ile ilgili Ölçütlerin Endüstri Ürünleri Tasarımı Bölümlerinin Öğretim Programlarına Entegrasyonu, İstanbul Teknik Üniversitesi Fen Bilimleri Enstitütsü, Doktora Tezi, İstanbul. 